\title{
Risks and management of pregnancy in women with epilepsy: a review
}

\author{
Mamta Mahajan ${ }^{1 *}$, Anita Pal ${ }^{2}$ \\ ${ }^{1}$ Department of Obstetrics and Gynecology, Government Civil Hospital, Theog, District Shimla, Himachal Pradesh, \\ India \\ ${ }^{2}$ Department of Obstetrics and Gynecology, Kamla Nehru State Hospital for Mother and Child, Indira Gandhi Medical \\ College, Shimla, India
}

Received: 24 January 2018

Accepted: 28 February 2018

*Correspondence:

Dr. Mamta Mahajan,

E-mail: drmamtamahajan@gmail.com

Copyright: $\odot$ the author(s), publisher and licensee Medip Academy. This is an open-access article distributed under the terms of the Creative Commons Attribution Non-Commercial License, which permits unrestricted non-commercial use, distribution, and reproduction in any medium, provided the original work is properly cited.

\begin{abstract}
Women with epilepsy (WWE) face certain challenges during their pregnancy. In the present article an effort has been made to review the information regarding the frequency of seizure in pregnancy, effects of epileptic seizure on fetus, complications during pregnancy and delivery, incidences of fetal congenital malformations and infant development. The article reviews these concerns with special emphasis on management of pregnancy. Recommendations concerning prenatal counselling, anti-epileptic drug management, breast feeding and contraception are also taken up in the later part of the article.
\end{abstract}

Keywords: Anti-epileptic drugs (AED), Congenital malformation, Epilepsy, Pregnancy

\section{INTRODUCTION}

Handling a chronic medical illness in pregnant women can be a tough task that can test a physician's expertise. The decision to treat the patient is the outcome of concern of several incessant factors. This is mainly evident in case of epilepsy, in which the condition itself poses health hazards for both pregnancy and the patient. Hence, physicians often sensibly take decisions while treating a patient, to make sure that the patient gets suitable care while curtailing the threats. "Epilepsy" is a Greek word meaning "to seize upon". In 1870, Hughlings Jackson, a British neurologist defined epilepsy as "... an intermittent derangement of nervous system due to an excessive and disorderly discharge of cerebral nervous tissue on muscles..."

An estimated $0.2 \%$ to $0.7 \%$ of pregnant female suffer from epilepsy, the most common major neurological complication during the pregnancy. While approximately over 1.5 million women with epilepsy (WWE) in India are of child bearing age, to meet their needs, managing maternal epilepsy and monitoring the health of developing fetus remains one of the most perplexing and engaging issues for all healthcare professionals. 1 The modern management of epilepsy which combines the use of improved anticonvulsants with a more sympathetic attitude towards the disability encourages the epileptic to marry. Pregnancy in the epileptic condition has therefore, become a more common therapeutic problem and for better outcome it is important for all healthcare professionals to know what curative measures are necessary to control epileptic attack during the gestation. This article reviews the major risks that epilepsy and Anti-Epileptic Drugs (AED's) have for pregnant women with epileptic problem.

\section{PRE-CONCEPTION COUNSELLING}

In developing countries where access to obstetrician and neurologist may not be possible, counseling with subsequent assessment and care can be provided by 
general practitioners if aware of impact of different AEDS. Since $50 \%$ of the pregnancies are unplanned, reproductive issues should be raised and discussed, by healthcare provider once WWE becomes sexually active, to allow informed and well-considered choices. Healthcare professionals must be sensitive to patient's anxieties and be prepared to manage both their seizures and emotional concerns. Women should be reassured that clear majority of pregnancy ends in safe confinement and healthy babies guidelines and recommendations to be discussed with WWE and their partners can be summarized as follows;

- Optimize treatment before conception;

- If AED is needed, use monotherapy;

- Choose the most effective AED for seizure and syndrome;

- Use lowest effective dose; and

- Avoid high peak levels of drug used by using multiple doses or extended release formulations.

\section{IMPACT OF PREGNANCY ON SEIZURE CONTROL}

In general, nearly a third of WWE experience increase in seizure frequency while other third experience a decrease in seizure frequency and others have no change in seizure frequency. In European and International Registry of Antiepileptic Drug in Pregnancy (EURAP) study, with 1718 cases showed that $92.7 \%$ WWE remained seizure free, $15.9 \%$ had improvement in seizure control in second and third trimesters as compared to the first and $17.3 \%$ had worst seizure control. ${ }^{2}$

In an analysis of seven years outcome data from the Australian register of anti-epileptic drugs in pregnancy it was found that epilepsies that were active in the year before pregnancy tend to increase the risk of intra-partum and post-partum seizures. ${ }^{3}$ The risk of seizure during the pregnancy was $50 \%$ to $70 \%$ less if the pre-pregnancy year was seizure free and decreased relatively little more with longer periods of pre pregnancy seizure control.

\section{HORMONAL}

Estrogens acts as pro-convulsant while progesterone increases seizure threshold making seizure less likely. Estrogens can increase activity at both N-methyl-Daspartate (NMDA) and non-NMDA glutamate and the net effect manifests as increased excitability. ${ }^{4}$

\section{METABOLIC FACTORS CAUSING INCREASE IN SEIZURE FREQUENCY}

Increased levels of circulating estrogens also increase function of P450 enzyme which leads to more rapid hepatic metabolism of anti-epileptic drugs. Physiological changes during pregnancy which have their implications on drug disposition are summarized in Table 1 . The metabolism of nearly every epileptic drug increases, resulting in lower blood levels, in case the adjustments are not made. Maternal plasma concentration of levetiracetam during third trimester is about $40 \%$ of baseline concentration without pregnancy, which suggests that therapeutic monitoring can be of value. ${ }^{5}$

Table 1: Physiologic changes during pregnancy: effects on drug disposition.

\begin{tabular}{|ll|}
\hline $\begin{array}{l}\text { Parameters } \\
\text { and extracellular fluid }\end{array}$ & Consequence \\
\hline Increased fat stores & $\begin{array}{l}\text { Decreased elimination of } \\
\text { lipid soluble drugs }\end{array}$ \\
\hline Increased cardiac output & $\begin{array}{l}\text { Increased hepatic blood } \\
\text { flow leading to increased } \\
\text { hepatic elimination }\end{array}$ \\
\hline $\begin{array}{l}\text { Increased renal blood } \\
\text { flow and glomerular } \\
\text { filtration rate }\end{array}$ & $\begin{array}{l}\text { Increased renal clearance } \\
\text { of unchanged drug }\end{array}$ \\
\hline $\begin{array}{l}\text { Altered cytochrome P- } \\
\text { 450 activity }\end{array}$ & $\begin{array}{l}\text { Altered systemic } \\
\text { absorption and hepatic } \\
\text { elimination }\end{array}$ \\
\hline $\begin{array}{l}\text { Decreased maternal } \\
\text { albumin }\end{array}$ & $\begin{array}{l}\text { Altered free drug fraction } \\
\text { Increased availability of } \\
\text { drug for hepatic extraction. }\end{array}$ \\
\hline
\end{tabular}

\section{EFFECTS OF EPILEPSY ON PREGNANCY}

Ninety percent of the WWE have uneventful pregnancies, but the incidence of obstetrics complications is higher. Spontaneous abortion is also a common event and may complicate up to $20 \%$ of pregnancies in WWE, although the data regarding the risk of abortion in WWE is extremely limited and conflicting. ${ }^{2}$ Several complications of pregnancy have been reported to occur more frequently in WWE than in general population. These include: vaginal hemorrhage, placental abruption, pregnancy induced hypertension and intrauterine growth retardation. ${ }^{6}$ Studies comparing still birth rates, found higher rates in infants of mothers with epilepsy $(1.3 \%$ to $14 \%$ ) than in infants of mothers without epilepsy. Studies have demonstrated increased rates of neonatal and perinatal deaths. ${ }^{7}$ Data from Kerala registry of epilepsy and pregnancy indicate WWE have not increased the risk complication of pregnancy or caesarian section. ${ }^{8}$

\section{EFFECTS OF EPILEPSY AND AED ON OFFSPRING}

These can be classified as fetal risk, Neo-natal problems and long-term concerns.

\section{Fetal Risks}

\section{Anthropometric changes}

Low birth weight, reduced length and head circumference have been observed in certain studies in WWE on AED. Hvas CL et al. in their study on 193 pregnant WWE 
observed that mean birth weight adjusted for gestational age was reduced by $102 \mathrm{gm}$ in children of WWE as compared to women without epilepsy. The weight reduction was most distinct in the children of women who received carbamazepine and oxcarbazepine monotherapy. ${ }^{9}$

\section{Malformations}

The major malformations most commonly associated with AEDs exposure include, congenital heart disease, cleft lip/palate, urogenital defects and neural tube defects. WWE treated with AED have an overall 2-3-fold increased risk of congenital malformation as compared to general population. ${ }^{10}$ The chance of a minor anomaly with an infant exposed to AED is roughly 2.5 times the risk in general population.

The first generation of AED Phenobarbital (PB) and phenytoin (PHT) are mainly associated with heart defects and facial clefts. Phenytoin (Fetal hydantoin) syndrome most commonly has hypoplastic phalanges, cleft palate, hair-lip, micro cephaly, hypertelorism, mental retardation and other cognitive impairment. The second-generation AEDs, Valproate (VPA) and Carbamazapine (CBZ) are primarily associated with spinabifida aperta (valproate), neural tube defects (CBZ), hypospadias (both), radial aplasia (rare but valproate specific) and probably autismlike disorder (valproate).

Fetal valproate syndrome was recognized by DiLiberti et al. The syndrome includes above anomalies which were reported to be very distinctive with a ridged metopicsuture, short-anteverted nose, broad nasal bridge and small mouth with thin upper lip and averted lower lip. Overlapping toes and joint laxity are also common findings. It comprises of learning and behavioral abnormalities. Developmental milestones are often delayed particularly in speech. ${ }^{11}$ Ornoy et al. studied the effect of carbamazepine monotherapy on forty-seven children and concluded that inutero exposure to carbamazapine results in carbamazapine syndrome, which is characterized by facial dysmorphic features and mild mental retardation. Facial dysmorphic features include short nose, long philtrum, up-slanting palpebral fissures, hypertelorism, epicanthal folds and nail hypoplasia. $^{12}$

The risk of malformation increases with increased dosage of AED specially CBZ and VPA. In a study by Samren, et al, offspring of mothers on valproate with more than $1000 \mathrm{mg} /$ day were at significantly increased risk of MCM, especially NTDs as compared to offspring of those exposed to less than $600 \mathrm{mg} /$ day of valproate. The incidence of malformations in fetus exposed to AED monotherapy is $10.3 \%, 5 \%$ and $6.7 \%$ for sodium valproate, phenytoin and $\mathrm{PB}$ respectively. ${ }^{13,14}$

Third generation of AED's consists of a large number of structurally related or different compounds, some of which have teratogenic activity in pre-clinical animal experiments, but none have sufficient human pregnancy experience to assess their safety when use by pregnant WWE. Most new drugs are first applied in an add-on regime. This implies polytherapy and increases risk of teratogenicity. The U.K. registry reported major malformation rates of $2.3 \%(1.4-3.7 \%)$ for CBZ $(\mathrm{n}=$ $700), 5.9 \%(4.3-8.2 \%)$ for VPA $(n=572)$, and $2.1 \%(1.0-$ $4.0 \%$ ) for lamotrigine (LTG; $n=390)$, all in monotherapy. ${ }^{15}$ There is a difference in malformation rate when lamotrigine is used as polytherapy with valproic acid $(10 \%)$ or as polytherapy without valproic acid $4.3 \%$. The malformations attributed to lamotrigine monotherapy in international lamotrigine pregnancy registry were esophageal malformation, cleft pallate and club foot. ${ }^{8}$ The preliminary results indicate that LTG may have a less teratogenic potential than VPA but several other factors need to be taken into consideration. LTG has lower efficacy against idiopathic generalized epilepsy when compared with sodium valproate.

Nicholson et al. studied 962 patients with idiopathic generalized epilepsy, one year remission was highest $(52.1 \%)$ for a person on VPA monotherapy and lower for those using topiramate (34.6\%) and LTG (16.7\%) monotherapy. Patient on LTG experienced increased seizure frequency during pregnancy because LTG is eliminated much faster than during non-pregnant state. Its clearance increases at least two folds during the pregnancy. The concentration of LTG in breast milk is higher than for other AED's. ${ }^{16-18}$ Moore et al undertook a clinical study of 57 children with fetal anticonvulsant syndrome and identified several features previously unrecognized or under reported in these syndromes. These include glue ear, connective tissue problems (including joint laxity), ocular and refractive disorders, laryngeal anomalies and autism or autistic spectrum behavioural problems. Developmental delay, particularly speech delay was common. The recurrence risk after a first affected child was high at $55 \%$ which may reflect an underlying genetic predisposition. ${ }^{19}$

\section{Neo-Natal problems}

Hemorrhage secondary to coagulation defects and sedative effect.

\section{Neo-natal hemorrhage}

The hemorrhage appears to result from deficiency of vitamin $\mathrm{K}$ dependent clotting factors II, VII, IX and $\mathrm{X}$ if WWE on Anti-convulsant (CBZ, PHT, PB and primidone) that induce the cytochrome 450 enzyme system

\section{Sedative effect}

PB, primidone and ethosuximide can reach concentrations in breast milk that may sedate the infant who should be monitored for signs of poor feeding, lethargy or hypotonia. 


\section{Long term fetal outcome}

The background risk of developing idiopathic epilepsy in general population is of the order of $0.5 \%$ to $1.0 \%$. But this risk is increased four folds in the offspring of WWE. ${ }^{20}$

Pennell et al, acquired data from several ongoing pregnancy registries, found that cognitive outcome in children of WWE reported an increased risk of mental deficiency, affecting $1.4 \%$ to $6.0 \%$ of children of WWE compared with $1 \%$ of controls. ${ }^{21}$ Eador et al, in a prospective study from 1999 to 2004 observed the cognitive function at three years of age after fetal exposure to AED's. ${ }^{22}$

The results showed that at three years of age children who had been exposed to valproate inuetro had significant lower IQ scores than those who had been exposed to another AED's. After adjustment for maternal IQ, maternal age, AED dose, gestational age at birth and maternal preconception use of foliate the mean IQ with various drugs is shown in Table 2. The finding supports the recommendations that valproate should not be used as a first-choice drug in women of child bearing age

Table 2: IQ scores of children at 3 years of age according to in Utero exposure to antiepileptic drugs.

\begin{tabular}{|lllll|}
\hline Variable & Carbamazepine & Lamotrigine & Phenytoin & Valproate \\
\hline Mean IQ (95\% CI) & $98(95-102)$ & $101(98-104)$ & $99(99-104)$ & $92(88-97)$ \\
\hline $\begin{array}{l}\text { Mean difference in IQ from } \\
\text { Valproate group (95\% CI) }\end{array}$ & $6(0.6-12.0)$ & $9(3.1-14.6)$ & $7(0.2-14.0)$ & \\
\hline P value & 0.04 & 0.009 & 0.04 & \\
\hline
\end{tabular}

\section{MANAGEMENT OF WOMEN WITH EPILEPSY (WWE) DURING PREGNANCY}

Early USG to date the pregnancy: When a pregnant WWE initially presents, the gestational age of the fetus must be established with reasonable accuracy. As WWE usually have irregular cycles one cannot rely on last menstrual period alone.

Monotherapy of AED at lowest effective dose should be advised. Frequent smaller doses or extended release preparations are preferred to decrease the peak plasma levels so that fetal exposure can be minimized.

Monitoring of serum AED levels is mandatory during each trimester of pregnancy. Many neurologists recommend monthly anti-epileptic drug levels during pregnancy as changes in the blood levels can occur rapidly. In case of highly protein bound AED free drug levels to be measured whereas, of minimally protein bound drugs total drug level should be obtained. Drug level should be measured immediately before next dose to confirm that the dosing is adequate.

Selenium supplementation in a dose of $200 \mu \mathrm{g}$ per day may be important to minimize the free radical mediated damage.

Folic acid supplementation in a dose of $5 \mathrm{mg} /$ day is advised for WWE using AED, which should not exceed an oral dose of $5 \mathrm{mg}$ /day but probably a lower dose $(0.5$ to $1 \mathrm{mg}$ )/day is sufficient. Side effects of folic acid therapy are few but doses of over $5 \mathrm{mg} /$ day could impair seizure control.

\section{PERINATAL DIAGNOSTIC TECHNIQUES}

Perinatal diagnostic techniques recommended as:

- Anamtomic USG at 11-13 weeks to identify the neural tube defects

- Maternal serum alpha pheto protein at 14-16 weeks

- Repeat anatomic USG at 16-20 wks. To identify the abnormalities as orofacial clefts, heart defects and cadual nural tube defects fetal echo can also be done at this time.

- USG at 33-34 weeks to monitor the fetal growth.

\section{VITAMIN K SUPPLEMENTATION}

If AED used by the mother is an enzyme inducer, the deficiency of vitamin $\mathrm{K}$ dependent coagulation factors can occur. This problem should be treated with 20 $\mathrm{mg}$ /day of oral Vitamin $\mathrm{K}$ beginning at $36 \mathrm{wks}$. of gestation until delivery or 2 doses of paranteral vitamin $\mathrm{K} 110 \mathrm{mg}$ at 34 and $36 \mathrm{wks}$. of gestation. The infant should receive an intramuscular injection of Vitamin K (1 $\mathrm{mg}$ at birth). If two of the Vitamin $\mathrm{K}$ dependent coagulation factor in the neonate (II, VII, IX and X) are below $5 \%$ of normal then fresh frozen plasma should be given.

\section{MANAGEMENT OF WWE DURING LABOR AND DELIVERY}

Serum levels of AEDs must be checked and all healthcare providers in the labor room must be informed that the patient has epilepsy. The obstetricians should plan the type of delivery based on the obstetrical indications. 
Vaginal delivery is the route of choice. The indications for caesarean section in WWE are shown in Table 3.

Table 3: Indications for caesarean section in WWE.

\begin{tabular}{|c|c|}
\hline $\begin{array}{l}\text { Elective caesarean } \\
\text { section }\end{array}$ & $\begin{array}{l}\text { Emergency caesarean } \\
\text { section }\end{array}$ \\
\hline $\begin{array}{l}\text { Substantial neurologic or } \\
\text { mental retardation }\end{array}$ & \multirow{6}{*}{$\begin{array}{l}\text { Generalized seizures } \\
\text { during labor or near term } \\
\text { Fetal asphyxia } \\
\text { Other obstetric } \\
\text { indications }\end{array}$} \\
\hline $\begin{array}{l}\text { - Reduced cooperation } \\
\text { of the patient for labor }\end{array}$ & \\
\hline $\begin{array}{l}\text { Very poor control of } \\
\text { seizures }\end{array}$ & \\
\hline $\begin{array}{l}\text { Daily complex partial } \\
\text { seizures } \\
\text { - Weekly tonic colonic } \\
\text { seizures }\end{array}$ & \\
\hline Uterine inertia & \\
\hline $\begin{array}{l}\text { - Failure of induction of } \\
\text { labor } \\
\text { - } \quad \text { Heavy sedation for } \\
\text { patient }\end{array}$ & \\
\hline
\end{tabular}

Labor management should be based on routine standards of care. Epidural analgesia is generally preferred. Pethidine should not be used as it is metabolized to norpethidine which is epileptogenic. Anti-epileptic drug should be administered as per schedule. If oral absorption is erratic, intravenous route is preferred especially in case of PHT and valproic acid. In case of carbamazapine extended release formulation can be used. Benzodizapines should be avoided as it leads to neonatal cardiac and respiratory depression. Close monitoring of mother and neonate is mandatory. If breakthrough seizure occurs it is treated with IV 1-2 mg of diazepam. If not controlled, then load phenytoin $1 \mathrm{gms}$ is recommended over one hour. Any female having seizure during the labor must be closely observed for next seventy-two hours.

\section{Status epilepticus}

Status epilepticus can occur in 1-4\% of women in labor. Fetal heart rate must be examined and Eclampsia should always be ruled out. General guidelines for managing SE can be followed in such instances.

\section{Postpartum management}

The AED need to be followed using the same third trimester dosage in first three months of post-partum period.

\section{Monitoring of AED levels}

AED monitoring should continue 6-12 weeks postpartum as normal metabolism returns 2-3 months after delivery. Any increase in drugs during pregnancy will need to be decreased slowly to pre-pregnancy doses over 3-4 weeks to avoid toxicity. An exception to this is lamotrigine, its metabolism returns back to normal within a few weeks requiring a more rapid adjustment of the doses. ${ }^{17}$

\section{Breast feeding}

Breast feeding should be encouraged as the benefits far outweigh the disadvantages. Feeds may be given before women take her AED doses. Most AED's tend to cross into breast milk (Table 4) including the neogeneration AED. ${ }^{5,17,18,23}$

Table 4: Anti-epileptic drugs in breast milk as a proportion of blood levels.

\begin{tabular}{|l|l|}
\hline Drug & $\begin{array}{l}\text { Proportion appearing } \\
\text { in breast milk }\end{array}$ \\
\hline Valproate & $<10 \%$ \\
\hline Phenytoin & $20 \%$ \\
\hline Carbamazpine & $40 \%$ \\
\hline Phenobarbitone & $50 \%$ \\
\hline Primidone & $80 \%$ \\
\hline Lamotrigine & $61 \%$ \\
\hline Topiramate & $86 \%$ \\
\hline Oxcarbazepine & $80 \%$ \\
\hline
\end{tabular}

\section{Contraception}

Enzyme inducing AED (PHT, CBZ, OXB and PB) stimulate activity of cytochrome P450 (CYP) and glucuronyl transferases (GT), hence, OCPs especially low estrogen preparation and progestrone may have reduced efficacy when used along with these drugs. It is recommended that a higher dose of estradiol be considered (>50 $\mu \mathrm{gms}$ ). Oxcarbazeoine, LTG, fellbamte and at dosages $\geq 200 \mathrm{mg}$ per day of topiramate, stimulate the metabolism of oral contraceptive steroids, possibly by tissue selective stimulation of CYP3A4.$^{24} \mathrm{~A}$ spermicidal gel or a barrier method could be used in addition to the pill to increase the level of protection. Anti AED drug effect on hormonal contraceptive agents are shown in Table 5 .

Table 5: Anti-epileptic drug effects on hormonal contraceptive agents.

\begin{tabular}{|ll|}
\hline Lowers hormone levels & No significant effect \\
\hline Phenobarbital & Ethosuximide \\
\hline Phenytoin & Valproate \\
\hline Carbamazapine & Gabapantin \\
\hline Primidone & Pregabalin \\
\hline Topiramate & Levetiracetam \\
\hline Oxcarbazepine & Zonisamide \\
\hline Felbamate & Tiagabine \\
\hline Lamotrigine & Vigabatrin \\
\hline
\end{tabular}

Intra-muscular medroxy progesterone (Dipoprovera) are other recommended options, injections be given every 10 rather than 12 weeks to women who are receiving 
enzyme inducing AED's. ${ }^{23,25}$ Prolonged use of AED along with medroxyprogestrone can result in bone loss. Sub-dermal levonorgestrel (Norplant) can be used but cases of contraceptive failure are high in women taking enzyme inducing AED.

- Mirena, releases levonorgestrel directly into uterine cavity, is found to be an effective contraceptive.

- Emergency contraceptive pill should contain $3 \mathrm{mg}$ of levonorgestrol as compared to $1.5 \mathrm{mg}$ in case of nonpregnant patient without epilepsy.

- Data on possible interaction between AED's and progesterone only pills, injections, patches and implants are very sparse.

- There is no contraindication for postpartum sterilization.

\section{HORMONAL THERAPIES HAVE BIDIRECTIONAL INTERACTIONS WITH AED'S}

Lamotrigene has been shown to have its levels reduced by addition of combined contraceptive steroids. Interestingly interaction follows a cyclic pattern with a marked decrease in LTG level during 21 days of estrogenic pill and a twofold rebound increase in AED concentration during pill free week. Other AEDs eliminated fully or partly by glucuronidation, such as valproate and possibly Oxcarbazapine could also show major changes in clearance following prescription offer combined contraceptive steroids. The drug interactions are unpredictable as they can be influenced by other drugs for example Co-medication with valproate appears to reduce or to prevent the increase in lamotrigine clearance caused by oral contraceptives. ${ }^{17}$

While additional exploration is undoubtedly desirable, there is also evidence that existing knowledge is not being effectively incorporated into healthcare. ${ }^{26}$ Nationallevel guidelines are required for treatment of epilepsy in women, which can handle a range of issues. Epilepsy causes disadvantages for women with epilepsy in pregnancy. While treating the pregnant epileptic woman, the potential harm of epilepsy to both mother and fetus itself must be considered against the potential harm of drug treatments. ${ }^{27}$

\section{CONCLUSION}

Today, the majority of women with epilepsy can conceive and bear normal, healthy children. Some are direct results of seizures, some are due to drug treatment and some are secondary handicaps because of stigmatization. Combined efforts of attending neurologist and obstetricians with appropriate pre-conceptional management, improved diagnostic techniques and host of effective anti-epileptic drugs (AED's) vastly improves epilepsy management and reduce risks to the offspring. Moreover, the women with epilepsy who are pregnant must take part in the pregnancy registry, so that, particularly with the new anti-seizure medications, information regarding their use can be used to help them.

Funding: No funding sources

Conflict of interest: None declared

Ethical approval: Not Required

\section{REFERENCES}

1. Thomas, SV, Sudevan, R, Saxena, V. Management of epilepsy and pregnancy. J Obstet Gynecol India. 2009;2:115-23.

2. Kaplan PW, Norwitz ER, Ben-Menachem E, Pennell PB, Druzin M, Robinson JN et al. Obstetrics risk for women with epilepsy during pregnancy. Epilepsy Behav. 2007;11:283-91.

3. Vajda FJ, Hitchcock A, Graham J, O'brien T, Lander C, Eadie M. Seizure control in antiepileptic drugtreated pregnancy. Epilepsia. 2008 Jan 1;49(1):1726.

4. Kevill JW, Gonzalez-Toledo E. Epilepsy and Pregnancy. Neurological Disorders Pregnancy 2011:91-121.

5. Tomson T, Palm R, Källén K, Ben-Menachem E, Söderfeldt B, Danielsson B, Johansson R, Luef G, Öhman I. Pharmacokinetics of levetiracetam during pregnancy, delivery, in the neonatal period, and lactation. Epilepsia. 2007 Jun 1;48(6):1111-6.

6. Swartjes, JM, Gejin, HP Van. Pregnancy and epilepsy. Eur J Obstet Gynecol Reprod Biol. 1998;79:3-11.

7. Yerby MS, Kaplan P, Tran T. Risk and management of pregnancy in women with epilepsy. Cleve Clin $\mathbf{J}$ Med. 2004;71(2):S25-S37.

8. Thomas SV. Epilepsy and pregnancy. Curr Sci. 2002;82:720-30.

9. Hvas CL, Henriksen TB, Dam M. Epilepsy and pregnancy: effect of antiepileptic drugs and lifestyle on birthweight. BJOG. $2000 \mathrm{Jul}$;107(7):896-902.

10. Dolk H, McElhattan P. Assessing epidemiological evidence for the teratogenic effects of anticonvulsant medication. J Med Genet. 2002;39:243-4.

11. Barrett C, Richens A. Epilepsy and pregnancy: Report of an epilepsy research foundation workshop. Epilepsy Res. 2003;52:147-87.

12. Ornoy A, Cohen E. Outcome of children born to epileptic mothers treated with carbamazepine during pregnancy. Arch Dis Child. 1996;75:517-20.

13. Samren EB, Duijn CV, Koch S, Hiilesmaa VK, Klepel H, Bardy $\mathrm{AH}$ et al. Maternal use of antiepileptic drugs and the risk of major congenital malformations: a joint European prospective study of human teratogenesis associated with maternal epilepsy. Epilepsia. 1997 Sep;38(9):981-90.

14. Panigrahi I, Kalra J. Antiepileptic drug therapy and overview of fetal effects. J Indian Med Assoc. 2011;109:108-10.

15. Tomson T, Perucca E, Battino D. Navigating toward fetal and maternal health: the challenge of Treating 
epilepsy in pregnancy. Epilepsia, 2004;45(10):11715.

16. Nicholson A, Appleton RE, Chadwick DW, Smith DF. The relationship between treatment with valproate, lamotrigine and topiramate and the prognosis of the idiopathic generalized epilepsies. J Neurol Neurosurg Psychiatry. 2004;75:75-9.

17. Pennell PB, Gidal BE, Sabers A, Gordon J, Perucca E. Pharmacology of antiepileptic drugs during pregnancy and lactation. Epilepsy Behav. 2007 Nov;11(3):263-9.

18. Ohman I, Vitols S, Tomsom T. Lamotrigine in pregnancy: Pharmacokinetics during delivery, in the neonate and during lactation. Epilepsia. 2000;41(6):709-13.

19. Moore, SJ, et al. A clinical study of 57 children with fetal anticonvulsant syndrome. J Med. Genet. 2000; 37:489-97.

20. Bridgette B. Management of epilepsy in pregnancy. Rec Adv Obstet and Gynecol. 2001;21:22-33.

21. Pennell PB. Using current evidence in selecting antiepileptic drugs for use during pregnancy. Epilepsy Curr. 2005;5(2):45-51.

22. Meador KJ, Baker GA, Browning N, Clayton-Smith J, Combs-Cantrell DT, Cohen $\mathrm{M}$ et al. Cognitive function at 3 years of age after fetal exposure to antiepileptic drugs. N Engl J Med. 2009;360:15971605 .
23. Öhman I, Vitols S, Luef G, Söderfeldt B, Tomson T. Topiramate kinetics during delivery, lactation, and in the neonate: preliminary observations. Epilepsia. 2002 Oct 1;43(10):1157-60.

24. Perucca E. Clinically relevant drug interactions with antiepileptic drugs. $\mathrm{Br} \mathrm{J}$ Clin Pharmacol. 2005;61(3):246-55.

25. Crawford P. Interactions between antiepileptic drugs and hormonal contraception. CNS drugs. 2002;16(4):263-72.

26. Fairgrieve SD, Jackson M, Jonas $\mathrm{P}$, Walshaw D, White K, Montgomery TL, Burn J et al. Population based prospective study of the care of women with epilepsy in pregnancy. BMJ. 2000;321:674-5.

27. Harden CL, Pennell PB, French JA, Davis A, Lau C, Llewellyn N, et al. Anti-mullerian hormone is higher in seizure-free women with epilepsy compared to those with ongoing seizures. Epilepsy Res. 2016;127:66-71.

Cite this article as: Mahajan M, Pal A. Risks and management of pregnancy in women with epilepsy: a review. Int J Reprod Contracept Obstet Gynecol 2018;7:1289-95. 